\title{
Research on Algorithm of Temperature Drop due to Throttling in Natural Gas Pipeline
}

\author{
Shiyao Peng \\ Petro China Pipeline Research \& Development Center, China \\ Junqi Tang \\ China University of Petroleum (Beijing) \\ Hang Yin \\ CNPC Southeast Asia Pipeline Company Limited \\ Guoqun Chen, Tao Yan \& Jianguo Zheng \\ Petro China Pipeline Research \& Development Center, China
}

\begin{abstract}
Using BWRS state equation, as well as two specific heat correlations, the temperature drop due to Joule-Thomson effect in natural gas pipeline is calculated and the algorithm of this is proposed. As for the west-to-east gas transmission pipeline, comparing the result calculated using the algorithm above with practical value measured, we find that the algorithm developed is steady and has a high accuracy of maximum deviation less than $1.42^{\circ} \mathrm{C}$, thus the algorithm can provide an accurate result for temperature drop calculation. KEYWORD: Gas pipeline; simulation; algorithm for temperature drop due to throttling; BWRS state equation; thermal physical parameters
\end{abstract}

\section{GENERAL INSTRUCTIONS}

There are many block valves and regulating valves in gas pipeline of long distance, big throughput and high pressure[1]. When gas is forced through a valve, the pressure is reduced and the temperature will drop dramatically. This phenomenon is called the Joule-Thomson effect (also known as the throttling effect). In the design, operation and management of gas pipeline, it is very important to calculate the temperature drop accurately.

This study deduces a feasible algorithm model for the temperature drop of natural gas based on the BWRS state equation. The transportation process of natural gas pipeline is accurately simulated; the calculated results are compared with the measured results and an optimal computing method for temperature drop is selected according to the comparison.

\section{CALCULATION OF THROTTLING TEMPERATURE DROP}

The physical parameters involved in the calculation of throttling temperature drop include natural gas density, specific heat at constant pressure, and most importantly, the Joule-Thomson coefficient. At present, there are mainly three ways to get the JouleThomson coefficient: Chart method, empirical formula method and equation of state method. But all of the above methods have shortcomings. The average $\mathrm{J}-\mathrm{T}$ coefficient got from the $\mathrm{H}-\mathrm{P}$ chart is inconvenient for calculation, because it doesn't reflect on the influence from the pressure, temperature and the composition of the natural gas. The empirical formula is fitted based on parts of measured data, whose application is very limited and accuracy is hard to meet the engineering requirement[2-4]. Currently, the engineering application is mainly based on the p-V-T state equation proposed by Van Der Waals, which can be divided into cubic equation of state (VDW, RK, SRK and PR) and multi-parameter equation of state (LKP and BWRS).

Previous researches deduced the calculation method of compression factor-temperature partial derivative based on the cubic equation of state[5]. The average relative errors for VDW, RK, SRK and PR cubic state equations are respectively $12.67 \%$, $2.31 \%, 1.85 \%$ and $7.61 \%$ through the comparison between calculation results and measured results. Obviously, SRK equation is optimal. However, the three state equations above cannot offer data which accurately describes the $\mathrm{p}-\mathrm{V}-\mathrm{T}$ property of substance, therefore more complicated multiparameter state equations are proposed. In 1970, Staling-Han proposed an improved equation of BWR (Benedict-Webb-Rubin) equation, which is exactly the BWRS equation, one of the most accurate equation for natural gas calculation. BWRS equation is with wide applicability and high accuracy. Previous research compared the average relative errors between calculation results and 
measured results, which are $-4.40 \%, 3.93 \%$ and $0.17 \%$ as for LKP、SRK、BWRS respectively. Moreover, the absolute value of maximum relative error of BWRS method is less than 5\%. We now choose BWRS equation to build the calculation model of J-T co efficiency.

\subsection{The BWRS State Equation}

The BWRS equation is a state equation of multiparameters[6]:

$$
\begin{aligned}
& p=\rho R T+\left(B_{0} R T-A_{0}-\frac{C_{0}}{T^{2}}+\frac{D_{0}}{T^{3}}-\frac{E_{0}}{T^{4}}\right) \rho^{2}+\left(b R T-a-\frac{d}{T}\right) \rho^{3} \\
& +\alpha\left(a+\frac{d}{T}\right) \rho^{6}+\frac{c \rho^{3}}{T^{2}}\left(1+\gamma \rho^{2}\right) \exp \left(-\gamma \rho^{2}\right)
\end{aligned}
$$

\section{In the equation above:}

$p$ - system pressure, $\mathrm{kPa}$;

$T$ - system temperature, $\mathrm{K}$;

$\rho-$ molar density of the gas or liquid, $\mathrm{kmol} \cdot \mathrm{m}^{-3}$; $R$ — the gas constant, $R=8.3143 \mathrm{~kJ} \cdot(\mathrm{kmol} \cdot \mathrm{K})^{-1}$.

\subsection{The Joule-Thomson Efficient}

According to the definition of Joule-Thomson effect, the ratio between the temperature drop and the pressure drop is called the Joule-Thomson efficient, which indicates the property of temperature changing with pressure before and after the throttle:

$$
D_{i}=\lim _{\Delta p \rightarrow 0}\left(\frac{\Delta T}{\Delta p}\right)_{H}=\left(\frac{\partial T}{\partial p}\right)_{H}
$$

Where $D_{i}=$ the Joule-Thomson efficient, $\mathrm{K} / \mathrm{Pa} ; T=$ the absolute temperature of gas, $\mathrm{K} ; p=$ the absolute pressure of gas, $\mathrm{Pa} ; H=$ gas enthalpy, $\mathrm{J} \cdot \mathrm{kmol}-1$.

According to Isenthalpic principle and thermodynamic general relations, equation (1) can be expressed as follows:

$$
D_{i}=\frac{-v+T\left(\frac{\partial v}{\partial T}\right)_{p}}{C_{p}}
$$

Where $v=$ the gas specific volume, $\mathrm{m} 3 \cdot \mathrm{kmol}-1 ; \mathrm{Cp}=$ the gas specific heat capacity at constant pressure per mole, $\mathrm{J} \cdot(\mathrm{kmol} \cdot \mathrm{K})-1$.

As the reciprocal relation of density and specific volume, the following correlation can be deduced from the thermal-dynamic relation:

$$
D_{i}=\frac{1}{C_{p}}\left[\frac{T}{\rho^{2}} \cdot \frac{\left(\frac{\partial p}{\partial T}\right)_{\rho}}{\left(\frac{\partial p}{\partial \rho}\right)_{T}}-\frac{1}{\rho}\right]
$$

Where $\rho=$ gas density, $\mathrm{kmol} \cdot \mathrm{m}^{-3}$.

The partial derivative and gas density involved in correlation (3) can be solved by the BWRS equation.
Take P's partial derivative with respect to T and $\rho$ respectively, we can get:

$$
\begin{aligned}
& \left(\frac{\partial p}{\partial T}\right)_{\rho}=\rho R+\left(B_{0} R+\frac{2 C_{0}}{T^{3}}-\frac{3 D_{0}}{T^{4}}+\frac{4 E_{0}}{T^{5}}\right) \rho^{2}+\left(b R+\frac{d}{T^{2}}\right) \rho^{3} \\
& -\frac{\alpha d}{T^{2}} \rho^{6}-\frac{2 c \rho^{3}}{T^{3}}\left(1+\gamma \rho^{2}\right) \exp \left(-\gamma \rho^{2}\right)
\end{aligned}
$$

$\left(\frac{\partial p}{\partial \rho}\right)_{T}=R T+2\left(B_{0} R T-A_{0}-\frac{C_{0}}{T^{2}}+\frac{D_{0}}{T^{3}}-\frac{E_{0}}{T^{4}}\right) \rho+3\left(b R T-a-\frac{d}{T}\right) \rho^{2}$

$+6 \alpha\left(a+\frac{d}{T}\right) \rho^{5}+\frac{3 c \rho^{2}}{T^{2}}\left(1+\gamma \rho^{2}-\frac{2}{3} \gamma^{2} \rho^{4}\right) \exp \left(-\gamma \rho^{2}\right)$

When solving gas density, the BWRS equation can be put in the form of function as follow:

$$
\begin{aligned}
& F(\rho)=\rho R T+\left(B_{0} R T-A_{0}-\frac{C_{0}}{T^{2}}+\frac{D_{0}}{T^{3}}-\frac{E_{0}}{T^{4}}\right) \rho^{2}+\left(b R T-a-\frac{d}{T}\right) \rho^{3} \\
& +\alpha\left(a+\frac{d}{T}\right) \rho^{6}+\frac{c \rho^{3}}{T^{2}}\left(1+\gamma \rho^{2}\right) \exp \left(-\gamma \rho^{2}\right)-p=0
\end{aligned}
$$

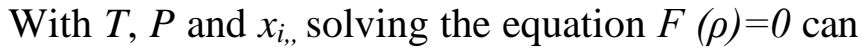
get the value of $\rho$. When solving the density with parabola method, the iterative formula is as follow:

$$
\rho_{k+1}=\frac{\rho_{k-1} F\left(\rho_{k}\right)-\rho_{k} F\left(\rho_{k-1}\right)}{F\left(\rho_{k}\right)-F\left(\rho_{k-1}\right)}
$$

where $K=$ the iteration number.

Two initial density should be assumed to determine a range when using the parabola method $^{[4]}$. The initial density is calculated under the hypothesis that it is the ideal gas. Set $\rho_{1}=0.0, \rho_{2}=\frac{p}{R T}$, and the terminal condition of iteration is : $\left|\rho_{k+1}-\rho_{k}\right| \leq \varepsilon \rho, \varepsilon_{\rho}=10^{-4}$. In general, the iterations are from 3 to 6 .

\subsection{Specific heat at constant pressure $\left(C_{p}\right)$}

The temperature drop calculated in equation (4) using the $C_{p}$ solved through BWRS equation has a large error when compared with measured data. As a result, we choose to create correlations fitting $C_{p}$ to substitute the state equation. In this way, the temperature drop calculated has a much smaller error than before.

The calculation formula acquired through the regression analysis is obtained by using the data in literature. For methane, the calculation formula acquired through the regression analysis is as follows[7]:

$C_{p}=1697.5107 p^{0.0661} T^{0.0776}$

In the equation: $C_{\mathrm{p}}-$ specific heat capacity at constant pressure, $\mathrm{J} \cdot(\mathrm{Kg} \cdot \mathrm{K})^{-1}$.

The gas specific heat capacity per mole is related with gas components, pressure and temperature, and 
it can be calculated with the following equation:

$C_{p}=13.19+0.092 T-6.24 \times 10^{-5} T^{2}+\frac{1.915 \times 10^{11} M_{g} p^{1.124}}{T^{5.08}}$

Where $C_{\mathrm{p}}=$ specific heat capacity per mole, $\mathrm{KJ} \cdot(\mathrm{kmol} \cdot \mathrm{K})^{-1} ; T=$ temperature, $\mathrm{K} ; M \mathrm{~g}=$ the average relative molecular mass; $p=$ pressure, $\mathrm{MPa}$.

\section{APPLICATION EXAMPLES}

In order to check the reliability of our algorithm and get the best calculating method, we use the commercial simulation software SPS and the localization simulation software Realpipe, along with the practical field data, to verify the algorithm.

The field data comes from the west-to-east gas transmission pipeline, Zhongwu pipeline, Seninglan pipeline, Zhongcang pipeline and Cangzi pipeline. As shown in table 1.

Table 1 Field Data of Gas Transmission Station

\begin{tabular}{|c|c|c|c|c|c|}
\hline \multirow[b]{2}{*}{ Pipeline } & \multirow[b]{2}{*}{ No. } & \multicolumn{2}{|c|}{ Pressure $\mathrm{p} / \mathrm{MPa}$} & \multicolumn{2}{|c|}{$\begin{array}{c}\text { Temperature } \\
\mathrm{T} /{ }^{\circ} \mathrm{C}\end{array}$} \\
\hline & & $\begin{array}{c}\text { Entering } \\
\text { the } \\
\text { station }\end{array}$ & $\begin{array}{l}\text { Exiting } \\
\text { the } \\
\text { station }\end{array}$ & $\begin{array}{l}\text { Entering } \\
\text { the } \\
\text { station }\end{array}$ & $\begin{array}{l}\text { Exiting } \\
\text { the } \\
\text { station }\end{array}$ \\
\hline \multirow{13}{*}{$\begin{array}{l}\text { West-to-east Gas } \\
\text { Transmission } \\
\text { Pipeline }\end{array}$} & 1 & 7.78 & 5.00 & 24.40 & 12.20 \\
\hline & 2 & 7.78 & 3.60 & 24.40 & 5.70 \\
\hline & 3 & 7.47 & 2.39 & 20.80 & -6.00 \\
\hline & 4 & 6.60 & 2.01 & 14.20 & -8.20 \\
\hline & 5 & 7.49 & 3.60 & 21.80 & 7.30 \\
\hline & 6 & 7.49 & 2.37 & 21.80 & 0.80 \\
\hline & 7 & 7.05 & 5.22 & 15.80 & 7.60 \\
\hline & 8 & 6.46 & 1.94 & 11.60 & -9.60 \\
\hline & 9 & 6.46 & 2.63 & 11.60 & -6.40 \\
\hline & 10 & 6.46 & 4.19 & 11.60 & 0.60 \\
\hline & 11 & 6.40 & 5.10 & 11.00 & 4.70 \\
\hline & 12 & 6.23 & 2.49 & 12.30 & -3.00 \\
\hline & 13 & 6.15 & 3.99 & 11.80 & 1.40 \\
\hline \multirow{6}{*}{$\begin{array}{l}\text { Zhongwu } \\
\text { Pipeline }\end{array}$} & 14 & 5.65 & 1.43 & 9.70 & -9.50 \\
\hline & 15 & 5.40 & 1.50 & 11.80 & -3.60 \\
\hline & 16 & 5.46 & 1.27 & 10.80 & -6.47 \\
\hline & 17 & 4.66 & 0.28 & 10.30 & -9.35 \\
\hline & 18 & 5.10 & 1.49 & 13.10 & -5.10 \\
\hline & 19 & 5.10 & 1.51 & 13.10 & -5.15 \\
\hline \multirow{4}{*}{$\begin{array}{l}\text { Seninglan } \\
\text { Pipeline }\end{array}$} & 20 & 3.96 & 3.86 & 2.60 & 2.10 \\
\hline & 21 & 4.13 & 1.02 & 4.00 & -12.70 \\
\hline & 22 & 3.93 & 0.70 & 1.50 & -10.00 \\
\hline & 23 & 3.40 & 1.45 & 2.80 & -6.00 \\
\hline $\begin{array}{l}\text { Zhongcang } \\
\text { Pipeline }\end{array}$ & 24 & 1.94 & 1.18 & 5.00 & 1.90 \\
\hline Cangzi Pipeline & 25 & 1.26 & 0.84 & 4.80 & 2.80 \\
\hline
\end{tabular}

Table 2 the Exiting Temperature Calculated by 5 Methods

\begin{tabular}{|c|c|c|c|c|c|c|}
\hline \multirow[b]{2}{*}{ Pipeline } & \multirow[b]{2}{*}{ No. } & \multicolumn{5}{|c|}{ The exiting temperature $/{ }^{\circ} \mathrm{C}$} \\
\hline & & $\begin{array}{c}\text { Method } \\
1\end{array}$ & $\begin{array}{c}\text { Method } \\
2\end{array}$ & $\begin{array}{c}\text { Method } \\
3\end{array}$ & $\begin{array}{c}\text { Method } \\
4\end{array}$ & $\begin{array}{c}\text { Method } \\
5\end{array}$ \\
\hline \multirow{13}{*}{$\begin{array}{l}\text { west-to-east } \\
\text { gas } \\
\text { transmission } \\
\text { pipeline }\end{array}$} & 1 & 12.06 & 10.97 & 13.96 & 13.52 & 11.77 \\
\hline & 2 & 5.83 & 2.15 & 8.24 & 7.55 & 4.56 \\
\hline & 3 & -3.53 & -9.16 & 0.07 & -0.84 & -4.94 \\
\hline & 4 & -9.07 & -13.98 & -5.63 & -6.51 & -10.52 \\
\hline & 5 & 4.15 & 0.92 & 6.43 & 5.77 & 2.96 \\
\hline & 6 & -2.36 & -8.14 & 1.11 & 0.20 & -3.95 \\
\hline & 7 & 7.55 & 6.70 & 8.41 & 8.10 & 6.98 \\
\hline & 8 & -12.03 & -17.10 & -9.18 & -10.52 & -13.59 \\
\hline & 9 & -7.99 & -11.61 & -5.81 & -6.91 & -9.29 \\
\hline & 10 & 0.58 & -0.76 & 1.56 & 0.95 & -0.19 \\
\hline & 11 & 4.25 & 4.35 & 5.32 & 4.99 & 4.41 \\
\hline & 12 & -6.77 & -10.08 & -4.52 & -5.58 & -8.01 \\
\hline & 13 & 1.27 & 0.08 & 2.30 & 1.73 & 0.56 \\
\hline \multirow{6}{*}{$\begin{array}{l}\text { Zhongwu } \\
\text { Pipeline }\end{array}$} & 14 & -13.46 & -18.15 & -9.29 & -10.79 & -14.48 \\
\hline & 15 & -9.12 & -12.85 & -5.25 & -6.58 & -9.99 \\
\hline & 16 & -12.04 & -16.44 & -7.82 & -9.28 & -13.05 \\
\hline & 17 & -14.10 & -18.36 & -9.44 & -10.98 & -15.37 \\
\hline & 18 & -6.00 & -9.02 & -2.38 & -3.58 & -6.77 \\
\hline & 19 & -5.89 & -8.87 & -2.29 & -3.48 & -6.65 \\
\hline \multirow{4}{*}{$\begin{array}{l}\text { Seninglan } \\
\text { Pipeline }\end{array}$} & 20 & -2.92 & 2.10 & 2.17 & 2.17 & 2.05 \\
\hline & 21 & -12.25 & -13.81 & -9.87 & -9.91 & -12.78 \\
\hline & 22 & -15.82 & -17.52 & -13.27 & -13.31 & -16.42 \\
\hline & 23 & -7.28 & -7.88 & -5.78 & -5.80 & -7.59 \\
\hline $\begin{array}{l}\text { Zhongcang } \\
\text { Pipeline }\end{array}$ & 24 & 0.85 & 0.70 & 1.60 & 1.32 & 0.56 \\
\hline $\begin{array}{l}\text { Cangzi } \\
\text { Pipeline }\end{array}$ & 25 & 2.51 & 2.45 & 2.91 & 2.76 & 2.35 \\
\hline
\end{tabular}

During the calculation, based on the BWRS state equation, we hope to get the best algorithm by using different solution formula of $C_{p}$. Together with the formula (9), (10), solution of $C_{p}$ [8] by BWRS and the Realpipe software, we have 4 different methods. Compare the results of these methods with the SPS simulation results. We have all the results shown in table 2.

Comparing the value measured in table 1 with the simulated results in table 2 , we evaluated the 5 methods from the following 3 aspects: their average absolute error, maximum absolute error and the proportion of the error $>3{ }^{\circ} \mathrm{C}$. The results are shown in table 3. 
Table 3 Error Analysis of the 5 Methods

\begin{tabular}{|l|l|l|l|l|l|}
\hline Methods & Method 1 & Method 2 & Method 3 & Method 4 & Method 5 \\
\hline Average absolute error $/{ }^{\circ} \mathrm{C}$ & 2.15 & 4.37 & 1.42 & 1.46 & 2.62 \\
\hline Maximum absolute error $/{ }^{\circ} \mathrm{C}$ & 5.82 & 9.97 & 6.07 & 5.16 & 6.58 \\
\hline Proportion of error $>3{ }^{\circ} \mathrm{C}$ & $36 \%$ & $60 \%$ & $8 \%$ & $8 \%$ & $36 \%$ \\
\hline
\end{tabular}

From the table above, we could see that: different solution of $C_{\mathrm{p}}$ has important effect on the calculation accuracy of the temperature drop due to throttling; overall, the method 3 and method 4 are better than the two programming methods and the SPS; although as for the average absolute error, the error of method 4 is $0.04^{\circ} \mathrm{C}$ bigger than that of method 3, when considering the error distribution, the method 4 has the minimum value of maximum absolute error $\left(5.16^{\circ} \mathrm{C}\right)$ and the minimum proportion $\left(5.16^{\circ} \mathrm{C}\right)$ that over the ideal error range, and the method 4 is more stale and reliable.

\section{CONCLUSIONS}

Based on the BWRS state equation and the fitting formula, we got the calculation formulas for various thermo-physical parameters and the detailed calculating procedures. A feasible algorithm is proposed and is realized by programming.

The specific heat volume has an obvious effect on the precision of temperature drop calculation. The precision and stability of fitting correlation is better than that of the BWRS method.

The algorithm proposed here is generally better than other algorithms. Compared with the value measured, the calculated results have a smaller value of maximum absolute error and the smaller proportion that over the ideal error range, and the calculated results are stale and reliable that can satisfy the need of production and provide theory basis for the temperature drop calculation due to throttling in the gas pipeline.

\section{REFERENCES}

[1] Jin Li. Application of the L-E-E Equation in the Calculation of Gas Physical Properties. Journal of Petrochemical Universities, 2007, 20(4):76-80.

[2] Yuxing Li Guangzhen Yao. The Design and Management of Gas Pipeline. Shandong: China University of Petroleum Press, 2009:26-68.

[3] Yezheng Wu etc. Refrigeration and Cryogenic Technology Principle. Beijing: Higher Education Press, 2007.

[4] Zhengyuan Dong Rongge Xiao. The BWRS method to calculate the Joule-Thomson coefficient. Oil \& Gas Storage and Transportation, 2007, 26(1):18-22.

[5] Wei Mao. Study of the calculation methods of the JouleThomson Coefficient. Special oil and gas field, 2002, 9(5):44-46.

[6] Tianming Guo etc. Equilibrium and Rectification of Polybasic Gas and Liquid. Beijing: Petroleum Industry Press, 2002: 64-68.

[7] Ke Gong Zhonghong Liang .Optimization Calculation of the Joule-Thomson Coefficient and its application in the production of High Pressure Gas Well's Throttling. Petroleum Geology and Engineering, 2008, 22(1):89-91.

[8] Yuguo WU Baodong Chen. Application of the BWRS Equation in the Calculation of Gas Physical Properties. Oil \& Gas Storage and Transportation, 2003, 22(10):16-21. 